\title{
Collagen IX gene polymorphisms and lumbar disc degeneration: a systematic review and meta-analysis
}

\author{
Huihong Wu' ${ }^{1}$, Siting Wang ${ }^{1}$, Weiyou Chen ${ }^{1}$, Xinli Zhan ${ }^{1}$, Zengming Xiao ${ }^{1}$, Hua Jiang ${ }^{1 *}$ and Qingjun Wei ${ }^{2}$
}

\begin{abstract}
Background: An increasing number of studies have investigated associations between collagen IX alpha 2 chain (COL9A2) and collagen IX alpha 3 chain (COL9A3) gene polymorphisms and the risk of lumbar disc degeneration (LDD). However, these studies have yielded contradictory results. The purpose of this meta-analysis is to investigate the association between the collagen IX gene polymorphisms (rs12077871, rs12722877, rs7533552 in COL9A2; rs61734651 in COL9A3) and LDD.

Methods: All relevant articles were collected from PubMed, Web of Science, and China National Knowledge Infrastructure (CNKI). The last electronic search was performed on September 1, 2017. The allele/genotype frequencies were extracted from each study. The odds ratio (OR) and $95 \%$ confidence interval (Cl) were used to assess the strength of associations under the five comparison genetic models. Statistical analysis was performed by Review Manager (RevMan) 5.31 software.
\end{abstract}

Results: The meta-analysis of 10 case-control studies, including 2102 LDD cases and 2507 controls, indicated that COL9A2 gene (rs12077871, rs 12722877, rs7533552) and COL9A3 gene (rs61734651) polymorphisms were not associated with LDD (rs12077871: T vs. C, $\mathrm{OR}=1.85,95 \% \mathrm{Cl}=0.87-3.91, P=0.11$; rs 12722877: $\mathrm{G}$ vs. $\mathrm{C}, \mathrm{OR}=0.83,95 \% \mathrm{Cl}=0.69-1.01$, $P=0.06 ;$ rs7533552: $\mathrm{G}$ vs. $\mathrm{A}, \mathrm{OR}=1.11,95 \% \mathrm{Cl}=0.98-1.25, P=0.09 ; \mathrm{rs} 61734651: \mathrm{T}$ vs. $\mathrm{C}, \mathrm{OR}=1.57,95 \% \mathrm{Cl}=0.51-4.84$, $P=0.43)$. The Egger text and the Begg funnel plot did not show any evidence of publication bias.

Conclusion: rs12077871, rs12722877, and rs7533552 variants in COL9A2 and rs61734651 variant in COL9A3 were not significantly associated with a predisposition to LDD. Large-scale and well-designed studies are needed to confirm this conclusion.

Keywords: COL9A2, COL9A3, Lumbar disc disease, Meta-analysis, Polymorphisms

\section{Background}

Low back pain (LBP) is a prevalent disease in adults, especially those ranging from 40 to 80 years of age [1]. LBP can be classified into two types: acute and chronic. Chronic LBP is characterized by persistent pain and a high risk of disability, which contributes to soaring medical costs and loss of labor, possibly leading to a critical impact on the social economy [2]. The major cause of LBP is lumbar disc degeneration (LDD) [3]. Although the pathogenesis of LDD is multivariate, genetic factors

\footnotetext{
*Correspondence: drjianghua@163.com

${ }^{1}$ Division of Spine Surgery, The First Affiliated Hospital of Guangxi Medical

University, No.6 Shuangyong Road, Nanning 530021, China

Full list of author information is available at the end of the article
}

have been reported to play an important role in LDD, including collagen I alpha 1 (COL1A1) gene, collagen IX alpha 1 chain (COL9A1) gene, collagen IX alpha 2 chain (COL9A2) gene, collagen IX alpha 3 chain (COL9A3) gene, vitamin $\mathrm{D}$ receptor gene, and cartilage intermediatelayer protein gene [4-7].

Collagen IX gene is one of the most recent trending research targets among numerous genes [8]. Collagen IX has been demonstrated to serve as a bridge between collagenous and non-collagenous proteins in normal tissues [9]. COL9A2 and COL9A3 genes encode $\alpha 2$ and $\alpha 3$ chains on collagen IX, respectively [10, 11]. To date, numerous groups have reported the associations of COL9A2 and COL9A3 gene polymorphisms with the risk of LDD. 
The first study, conducted by Annunen et al., suggested that COL9A2 gene polymorphism (rs12077871) was associated with LDD in the Finnish population [4]. Another study by Paassilta et al. in Finland suggested that rs12077871 was not relevant to LDD, but rs61734651 in COL9A3 gene was relevant to LDD [12]. A number of studies have been conducted on this topic. However, the results were generally inconsistent and inconclusive. Therefore, we collected all the relevant studies, including 2102 cases and 2507 controls, to perform a meta-analysis in order to investigate the association between COL9A2 and COL9A3 gene polymorphisms and LDD predisposition.

\section{Methods}

\section{Strategy for literature search}

The study was conducted by searching literature databases, including PubMed (http://www.ncbi.nlm.nih.gov/pubmed), Web of Science (http://www.isiknowledge.com/), and CNKI (China National Knowledge Infrastructure). To identify all possible studies, we used the following terms: "LDD" or "Lumbar disc disease" or "Lumbar disc degeneration" and "COL9A2" or "COL9A3" or "Collagen IX" or "Polymorphisms" or "COL9A"." No language or publication date restrictions were applied. The last electronic search was performed on September 1, 2017.

\section{Inclusion and exclusion criteria}

The following inclusion criteria were used to search eligible studies: (1) investigated the relationship of COL9A2 or COL9A3 gene polymorphisms with LDD, (2) casecontrol or cohort design, and (3) provided available data for the estimation of an odds ratio (OR) and 95\% confidence interval (CI). Studies were excluded according to the following criteria: (1) repeated publications, (2) reported in the form of comment and review, (3) irrelevant to LDD, and (4) unavailable allele and genotype frequencies. Two investigators (W.H.H and W.S.T) independently evaluated the articles for compliance with the inclusion and exclusion criteria. For disagreements, a consensus was reached by a third investigator (C.W.Y).

\section{Data extraction}

The following data were extracted from all the eligible articles: first author's name, publication year, country of enrollment, ethnicity, numbers of cases and controls, disease, diagnostic criteria, source of controls, genotyping methods, genotypes, and allele frequency of cases and controls. Data were extracted independently by two reviewers (W.H.H and W.S.T), and a third reviewer (C.W.Y) was needed for any disagreements.

\section{Methodological quality}

The methodological quality of the included studies was evaluated according to a quality evaluation form base in the Critical Appraisal Skills Programme (CASP) for casecontrol study [13]. The assessment of CASP contains 10 questions, which are associated with information given by single studies. There are three degrees for each question:

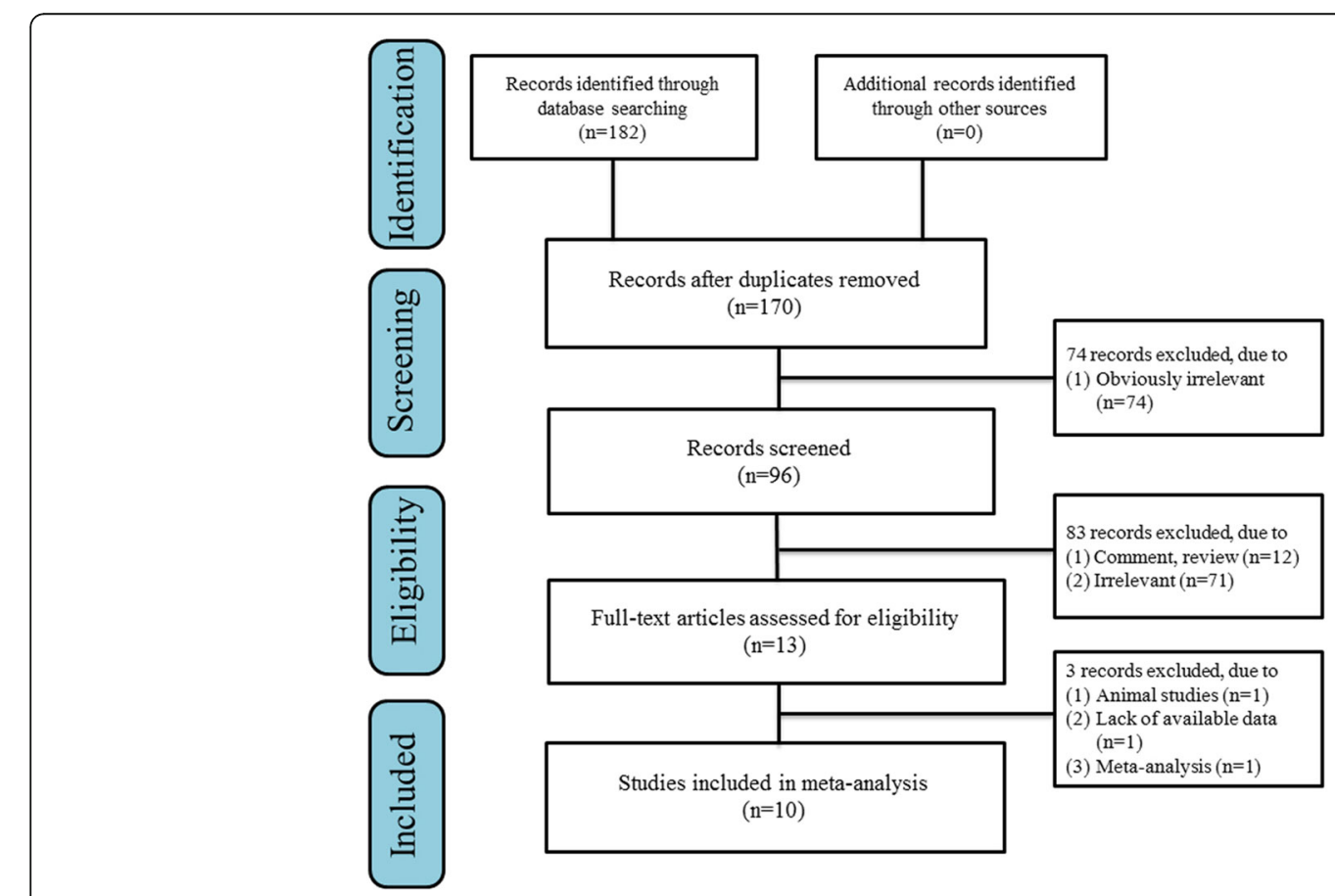

Fig. 1 Literature search flow diagram 
"yes" (scored 2), "can't tell" (scored 1), or "no" (scored 0). The maximum score is 20 , and the minimum score is 0 . Studies could be divided into three grades: grade A (high quality, scored 15-20), grade B (medium quality, scored $8-14$ ), and grade C (low quality, scored 0-7).

\section{Statistical analysis}

Meta-analysis was conducted using Revman 5.31 software (Nordic Cochrane Centre, Cochrane Collaboration, Copenhagen, Denmark). The pooled OR and 95\% CI were used to estimate the strength of correlations between COLA9A2 (rs12077871, rs12722877, rs7533552) and COL9A3 (rs61734651) variants and LDD. Heterogeneity was tested using the chi-square-based $Q$ test and $I^{2}$ test. To calculate the pooled OR, a fix effect model was performed if no heterogeneity existed $\left(P>0.05, I^{2}<50 \%\right)$. Otherwise, a random effect model was used. Five comparison genetic models were conducted to evaluate the association between the four single nucleotide polymorphisms (SNPs) (rs12077871, rs12722877, rs7533552, rs61734651) and LDD risk. Hardy-Weinberg equilibrium among controls was estimated using the HWE version 1.20 program (Columbia University, New York, NY). If there was heterogeneity in some models $\left(P<0.05, I^{2}>50 \%\right)$, we performed the sensitivity test to assess the possible influence of one study on the pooled OR. Studies were

Table 1 Characteristics of the case-control studies included in systematic review

\begin{tabular}{|c|c|c|c|c|c|c|c|c|c|}
\hline First author & Year & Population & Ethnicity & $\begin{array}{l}\text { Number of } \\
\text { cases/controls }\end{array}$ & Disease & $\begin{array}{l}\text { Diagnostic } \\
\text { criteria }\end{array}$ & Control group & $\begin{array}{l}\text { Genotyping } \\
\text { determination }\end{array}$ & CASP \\
\hline \multicolumn{10}{|l|}{ rs12077871 } \\
\hline Annunen et al. [4] & 1999 & Finland & Caucasian & $157 / 174$ & LDD & $\mathrm{MRI}, \mathrm{CT}$ & $\begin{array}{l}\text { Healthy normal without } \\
\text { spine-related problems }\end{array}$ & PCR-seq & 18 \\
\hline Noponen-Hietala et al. [15] & 2003 & Finland & Caucasian & $29 / 56$ & LDD & MRI, CT & $\begin{array}{l}\text { Patients without spine- } \\
\text { related problems }\end{array}$ & PCR-seq CSGE & 20 \\
\hline Seki et al. [17] & 2006 & Japan & Asian & $470 / 654$ & LDD & $M R I, P R$ & NM & PCR-seq & 19 \\
\hline Song et al. [18] & 2010 & China & Asian & $125 / 125$ & LDD & $M R I, P R$ & Patients without LDD & TaqMan assay & 18 \\
\hline Hyun et al. [14] & 2011 & Korean & Asian & 205/101 & LDD & MRI & $\begin{array}{l}\text { Patients without spine- } \\
\text { related problems }\end{array}$ & PCR-seq & 20 \\
\hline Rathod et al. [16] & 2012 & India & Asian & $100 / 100$ & LDD & MRI & $\begin{array}{l}\text { Patients without spine- } \\
\text { related problems }\end{array}$ & TaqMan assay & 19 \\
\hline \multicolumn{10}{|l|}{ rs12722877 } \\
\hline Paassilta et al. [12] & 2001 & Finland & Caucasian & $156 / 167$ & LDD & $\mathrm{MRI}, \mathrm{CT}$ & $\begin{array}{l}\text { Healthy normal, patients } \\
\text { with osteoarthritis }\end{array}$ & PCR-seq CSGE & 20 \\
\hline Seki et al. [17] & 2006 & Japan & Asian & $469 / 654$ & LDD & $M R I, P R$ & NM & PCR-seq & 19 \\
\hline Song et al. [18] & 2010 & China & Asian & $125 / 126$ & LDD & $\mathrm{MRI}, \mathrm{PR}$ & Patients without LDD & TaqMan assay & 18 \\
\hline Chen et al. [19] & 2013 & China & Asian & $280 / 268$ & LDD & $\mathrm{MRI}, \mathrm{CT}, \mathrm{PR}$ & Patients without LDD & TaqMan assay & 18 \\
\hline \multicolumn{10}{|l|}{ rs7533552 } \\
\hline Annunen et al. [4] & 1999 & Finland & Caucasian & $157 / 174$ & LDD & MRI, CT & $\begin{array}{l}\text { Healthy normal, patients } \\
\text { with osteoarthritis }\end{array}$ & PCR-seq & 18 \\
\hline Seki et al. [17] & 2006 & Japan & Asian & $470 / 654$ & LDD & MRI, PR & NM & TaqMan assay & 19 \\
\hline Song et al. [18] & 2010 & China & Asian & $125 / 125$ & LDD & MRI, PR & Patients without LDD & TaqMan assay & 18 \\
\hline Hyun et al. [14] & 2011 & Korean & Asian & 205/101 & LDD & MRI & $\begin{array}{l}\text { Patients without spine- } \\
\text { related and arthritic } \\
\text { problems }\end{array}$ & PCR-seq & 20 \\
\hline Meng et al. [20] & 2016 & China & Asian & $215 / 230$ & LDD & $\mathrm{MRI}, \mathrm{CT}$ & Healthy & PCR-seq & 19 \\
\hline \multicolumn{10}{|l|}{ rs61734651 } \\
\hline Paassilta et al. [12] & 2001 & Finland & Caucasian & $156 / 167$ & LDD & MRI, CT & $\begin{array}{l}\text { Healthy normal, patients } \\
\text { with osteoarthritis }\end{array}$ & PCR-seq CSGE & 20 \\
\hline Noponen-Hietala et al. [15] & 2003 & Finland & Caucasian & $29 / 56$ & LDD & MRI, CT & $\begin{array}{l}\text { Patients without spine- } \\
\text { related problems }\end{array}$ & PCR-seq CSGE & 20 \\
\hline Eskola et al. [21] & 2010 & Danish & Caucasian & $154 / 66$ & LDD & MRI & $\begin{array}{l}\text { Patients without spine- } \\
\text { related problems }\end{array}$ & PCR-seq & 19 \\
\hline Rathod et al. [16] & 2012 & India & Asian & $100 / 100$ & LDD & MRI & $\begin{array}{l}\text { Patients without spine- } \\
\text { related problems }\end{array}$ & TaqMan assay & 19 \\
\hline
\end{tabular}


removed, in turn, from the overall analysis. In addition, we performed subgroup analysis stratified by ethnicity. Funnel plots and Egger's tests were used to assess the potential publication bias.

It will be reasonable to estimate the combined effect from a group study if the effects found individually in studies are sufficiently similar. Some variation between the studies is expected because the estimates of the treatment effect are influenced by chance. What we need to know is whether there is more than just a chance-related variation. The heterogeneity test was performed to determine this extreme variation. Therefore, in this study, chi-square statistic was performed together with the degree of freedom. During the meta-analysis, the results were evaluated by incorporating suspicious relevance studies into statistical analyses. Then, these studies, the appropriateness of which were questionable, were excluded from the study and the same analyses were repeated. After comparing the two results, the data for the appropriate ones were interpreted.

\section{Results}

Characteristics of studies

As shown in Fig. 1, 182 potentially relevant studies were searched from the electronic database. Ten studies were identified by screening the full article, which included 2102 cases and 2507 controls (rs12077871 6 studies, 1086 cases, and 1210 controls; rs12722877 4 studies, 1030 cases, and 1235 controls; rs7533552 5 studies, 1172 cases, and 1287 controls; rs61734651 4 studies, 365 cases, and 631 controls). Of those, seven articles reported that gene polymorphism in two or more loci were associated with LDD risk. Table 1 and Table 2 show the main characteristics of included studies. The results of quality assessment are also shown in Table 1. All included studies were categorized as grade A, with scores ranging from 18 to 20 .

\section{Quantitative data analysis}

Association of rs12077871 and LDD susceptibility

The association between rs12077871 polymorphism and LDD predisposition was determined in six case-control

Table 2 Genotype and allele frequency of COL9A2 and COL9A3 gene polymorphisms in LDD patients and controls

\begin{tabular}{|c|c|c|c|c|c|c|c|c|c|c|c|c|c|}
\hline \multicolumn{3}{|l|}{ Study } & \multicolumn{5}{|c|}{ Case group } & \multicolumn{5}{|c|}{ Control group } & \multirow{2}{*}{$\begin{array}{l}\text { HWE for } \\
\text { control }\end{array}$} \\
\hline Author & Year & Ethnicity & 11 & 12 & 22 & 1 & 2 & 11 & 12 & 22 & 1 & 2 & \\
\hline \multicolumn{14}{|l|}{ rs12077871 (C vs. T) } \\
\hline Annunen et al. [4] & 1999 & Caucasian & NM & NM & NM & 308 & 6 & NM & NM & NM & 348 & 0 & \\
\hline Noponen-Hietala et al. [15] & 2003 & Caucasian & 28 & 1 & 0 & 57 & 1 & 56 & 0 & 0 & 112 & 0 & 1.000000 \\
\hline Seki et al. [17] & 2006 & Asian & 370 & 91 & 9 & 831 & 109 & 504 & 136 & 14 & 1144 & 164 & 0.184822 \\
\hline Song et al. [18] & 2010 & Asian & 95 & 30 & 0 & 220 & 30 & 100 & 24 & 1 & 224 & 26 & 0.735473 \\
\hline Hyun et al. [14] & 2011 & Asian & 155 & 46 & 4 & 356 & 54 & 76 & 22 & 3 & 174 & 28 & 0.377303 \\
\hline Rathod et al. [16] & 2012 & Asian & 43 & 43 & 15 & 128 & 72 & 83 & 17 & 0 & 183 & 17 & 0.352901 \\
\hline \multicolumn{14}{|l|}{ rs12722877 (C vs. G) } \\
\hline Paassilta et al. [12] & 2001 & Caucasian & NM & NM & NM & 290 & 22 & NM & NM & NM & 312 & 22 & \\
\hline Seki et al. [17] & 2006 & Asian & 414 & 54 & 1 & 882 & 56 & 576 & 76 & 2 & 1228 & 80 & 0.761095 \\
\hline Song et al. [18] & 2010 & Asian & 103 & 22 & 0 & 228 & 22 & 109 & 17 & 0 & 235 & 17 & 0.416784 \\
\hline Chen et al. [19] & 2013 & Asian & 158 & 98 & 24 & 414 & 146 & 120 & 113 & 35 & 353 & 183 & 0.306985 \\
\hline \multicolumn{14}{|l|}{ rs7533552 (C vs. G) } \\
\hline Annunen et al. [4] & 1999 & Caucasian & NM & NM & NM & 228 & 86 & NM & NM & NM & 258 & 90 & \\
\hline Seki et al. [17] & 2006 & Asian & 217 & 221 & 32 & 655 & 285 & 327 & 277 & 50 & 931 & 377 & 0.40912 \\
\hline Song et al. [18] & 2010 & Asian & 21 & 63 & 41 & 105 & 145 & 25 & 67 & 33 & 117 & 133 & 0.39295 \\
\hline Hyun et al. [14] & 2011 & Asian & 86 & 97 & 22 & 269 & 141 & 41 & 47 & 13 & 129 & 73 & 0.934487 \\
\hline Meng et al. [20] & 2016 & Asian & 68 & 113 & 34 & 249 & 181 & 81 & 131 & 18 & 293 & 167 & 0.000449 \\
\hline \multicolumn{14}{|l|}{ rs61734651 (C vs. T) } \\
\hline Paassilta et al. [12] & 2001 & Caucasian & 131 & 38 & 2 & 300 & 42 & 291 & 30 & 0 & 612 & 30 & 0.3798 \\
\hline Noponen-Hietala et al. [15] & 2003 & Caucasian & 25 & 3 & 1 & 53 & 5 & 56 & 0 & 0 & 112 & 0 & 1.000000 \\
\hline Eskola et al. [21] & 2010 & Caucasian & 57 & 9 & 0 & 123 & 9 & 123 & 30 & 1 & 276 & 32 & 0.566482 \\
\hline Rathod et al. [16] & 2012 & Asian & 95 & 5 & 0 & 195 & 5 & 93 & 7 & 0 & 193 & 7 & 0.716846 \\
\hline
\end{tabular}

11,12 , and 22 indicate $\mathrm{CC}, \mathrm{TC}$, and $\Pi$ for rs12077871; CC, CG, and GG for rs12722877; AA, GA, and GG for rs7533552; CC, TC, and T for rs61734651, respectively NM not mentioned 
Table 3 Association test and heterogeneity test of COL9A2 and COL9A3 gene polymorphisms (rs12077871, rs12727871, rs7533553, and rs61734657)

\begin{tabular}{|c|c|c|c|c|c|c|c|}
\hline \multirow[t]{2}{*}{ SNP } & \multirow[t]{2}{*}{ Genetic model } & \multirow{2}{*}{$\begin{array}{l}\text { Analysis } \\
\text { model }\end{array}$} & \multicolumn{3}{|c|}{ Test of association } & \multicolumn{2}{|c|}{ Heterogeneity test } \\
\hline & & & $\mathrm{OR}$ & $95 \% \mathrm{Cl}$ & $P$ value & $P(\%)$ & $P_{\text {het }}$ \\
\hline \multicolumn{8}{|c|}{ rs12077871 } \\
\hline & \multicolumn{7}{|l|}{ Allelic } \\
\hline & C vs. T & Random & 1.85 & {$[0.87,3.91]$} & 0.110 & 87 & $<0.00001$ \\
\hline & \multicolumn{7}{|l|}{ Codominant model } \\
\hline & CC vs. TT & Random & 1.55 & {$[0.26,9.16]$} & 0.630 & 74 & 0.01 \\
\hline & CT vs. TT & Random & 1.57 & {$[0.82,3.01]$} & 0.170 & 81 & 0.0004 \\
\hline & \multicolumn{7}{|l|}{ Dominant model } \\
\hline & $T+C T$ vs. CC & Fixed & 0.27 & {$[0.06 .1 .29]$} & 0.010 & 0 & 0.5 \\
\hline & \multicolumn{7}{|l|}{ Recessive model } \\
\hline & $C C+C T$ vs. $T T$ & Random & 1.7 & {$[0.79,3.64]$} & 0.180 & 87 & $<0.00001$ \\
\hline \multicolumn{8}{|c|}{ rs12722877 } \\
\hline & \multicolumn{7}{|l|}{ Allelic } \\
\hline & C vs. G & Random & 0.90 & {$[0.673,1.213]$} & 0.499 & 47.70 & 0.125 \\
\hline & \multicolumn{7}{|l|}{ Codominant model } \\
\hline & CC vs. GG & Fixed & 0.53 & {$[0.304,0.923]$} & 0.025 & 0 & 0.818 \\
\hline & CG vs. GG & Fixed & 0.79 & {$[0445,1.388]$} & 0.406 & 0 & 0.927 \\
\hline & \multicolumn{7}{|l|}{ Dominant model } \\
\hline & GG + CG vs. CC & Random & 1.13 & {$[0.746,1.722]$} & 0.556 & 63.70 & 0.064 \\
\hline & \multicolumn{7}{|l|}{ Recessive model } \\
\hline & $C C+C G$ vs. GG & Fixed & 0.63 & {$[0.367,1.072]$} & 0.088 & 0 & 0.93 \\
\hline \multicolumn{8}{|c|}{ rs7533552 } \\
\hline & \multicolumn{7}{|l|}{ Allelic } \\
\hline & A vs. G & Fixed & 1.11 & {$[0.983,1.253]$} & 0.092 & 0 & 0.658 \\
\hline & \multicolumn{7}{|l|}{ Codominant model } \\
\hline & AA vs. GG & Random & 1.26 & {$[0.807,1.902]$} & 0.310 & 46.60 & 0.132 \\
\hline & AG vs. GG & Random & 1.17 & {$[0.735,1.867]$} & 0.505 & 58.60 & 0.065 \\
\hline & \multicolumn{7}{|l|}{ Dominant model } \\
\hline & $G G+A G$ vs. AA & Fixed & 0.88 & {$[0.733,1.050]$} & 0.154 & 0 & 0.875 \\
\hline & Recessive model & & & & & & \\
\hline & $A A+A G$ vs. GG & Random & 1.21 & {$[0.784,1.879]$} & 0.384 & 56.70 & 0.074 \\
\hline \multicolumn{8}{|c|}{ rs61734651 } \\
\hline & \multicolumn{7}{|l|}{ Allelic } \\
\hline & C vs. T & Random & 1.57 & {$[0.51,4.84]$} & 0.430 & 81 & 0.001 \\
\hline & \multicolumn{7}{|l|}{ Codominant model } \\
\hline & CC vs. TT & Fixed & 3.93 & {$[0.83,18.60]$} & 0.080 & 0 & 0.44 \\
\hline & CT vs. TT & Random & 1.48 & {$[0.50,4.33]$} & 0.480 & 77 & 0.004 \\
\hline & \multicolumn{7}{|l|}{ Dominant model } \\
\hline & $\Pi+C T$ vs. CC & Fixed & 0.27 & {$[0.06,1.29]$} & 0.100 & 0 & 0.5 \\
\hline & \multicolumn{7}{|l|}{ Recessive model } \\
\hline & $C C+C T$ vs. TT & Random & 1.55 & {$[0.50,4.86]$} & 0.450 & 80 & 0.002 \\
\hline
\end{tabular}




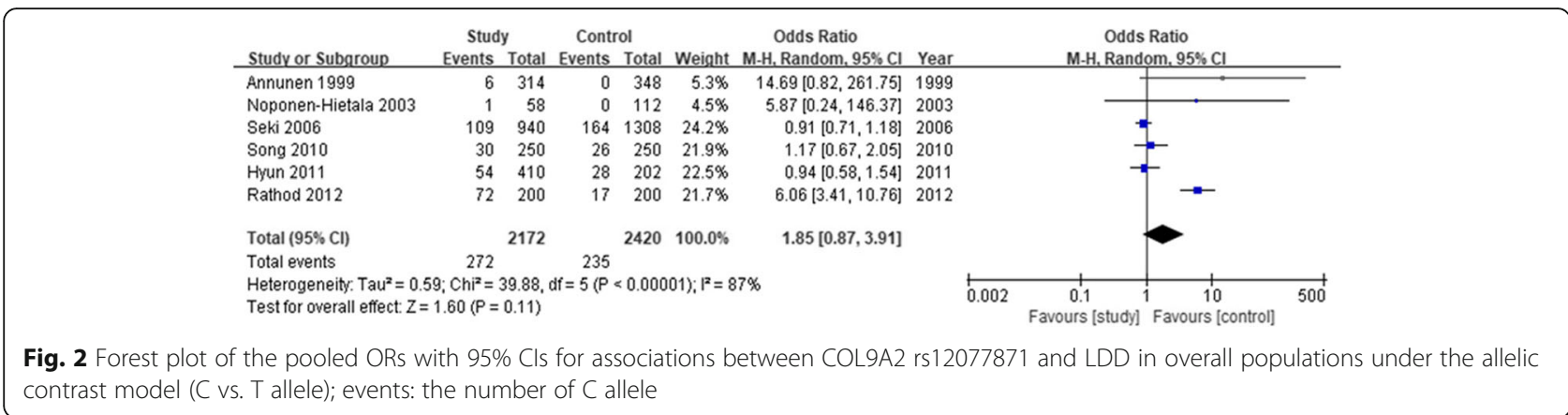

studies [4, 14-18], including 1086 cases and 1210 controls. As shown in Table 3, we evaluated the association between rs12077871 polymorphism and LDD predisposition under five genetic models ( $\mathrm{T}$ vs. $\mathrm{C}$ : $\mathrm{OR}=1.85,95 \% \mathrm{CI}=$ $0.87-3.91, P=0.11)$. Furthermore, we performed the subgroup analysis stratified by ethnicity. The result showed rs12077871 was not associated with LDD risk in the Asian population. The subgroup analysis of the Caucasian population was unavailable as there were insufficient studies. The forest plot of the allele contrast genetic model demonstrated the association between rs12077871 polymorphism and LDD susceptibility (Fig. 2).

\section{Association of rs 12722877 and LDD susceptibility}

The association between rs12722877 polymorphism and LDD predisposition was determined in four case-control studies [12, 17-19], including 1030 cases and 1215 controls. As shown in Table 3, we used five genetic models to access the relationship between rs12722877 polymorphism and LDD predisposition ( $G$ vs. C: $\mathrm{OR}=0.83$, 95\% CI $=0.69-1.01, P=0.06)$. Moreover, we performed the subgroup analysis stratified by ethnicity. For the Asian population, rs12722877 polymorphism was associated with LDD predisposition under the allele contrast genetic model $(\mathrm{OR}=0.81,95 \% \mathrm{CI}=0.67-0.99, P=0.04)$. However, a significant association was not found in other genetic models. The subgroup analysis of the Caucasian population was unavailable due to insufficient studies. The forest plot of the allele contrast genetic model indicated the association between rs12722877 polymorphism and LDD predisposition (Fig. 3).

\section{Association of rs7533552 and LDD susceptibility}

The association between rs7533552 polymorphism and LDD predisposition was determined in five case-control studies [4, 14, 17, 18, 20], including 957 cases and 1054 controls. As shown in Table 3, we implemented five genetic models to access the association between rs7533552 polymorphism and LDD predisposition ( $G$ vs. A: OR= $1.11,95 \% \mathrm{CI}=0.98-1.25, P=0.09)$. In addition, we performed the subgroup analysis stratified by ethnicity. The data showed rs7533552 polymorphism was not associated with LDD risk in the Asian population. The forest plot of the allele contrast genetic model demonstrated the association between rs7533552 polymorphism and LDD predisposition (Fig. 4).

\section{Association of rs61734651 and LDD susceptibility}

The association between rs61734651 polymorphism and LDD predisposition was determined in four case-control studies $[12,15,16,21]$, including 365 cases and 631 controls. As shown in Table 3, we evaluated the association between rs61734651 polymorphism and LDD predisposition under five genetic models ( $\mathrm{T}$ vs. $\mathrm{C}$ : $\mathrm{OR}=1.57,95 \%$ $\mathrm{CI}=0.51-4.84, P=0.43)$. Furthermore, we performed the subgroup analysis stratified by ethnicity. The result showed rs61734651 polymorphism was not associated with LDD susceptibility in the Caucasian population.

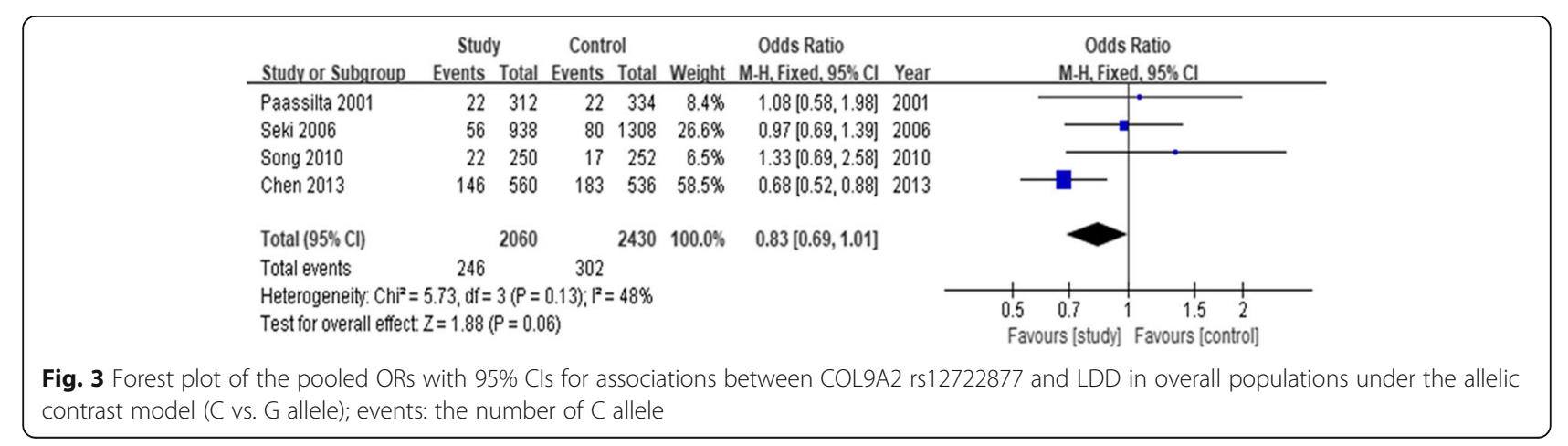




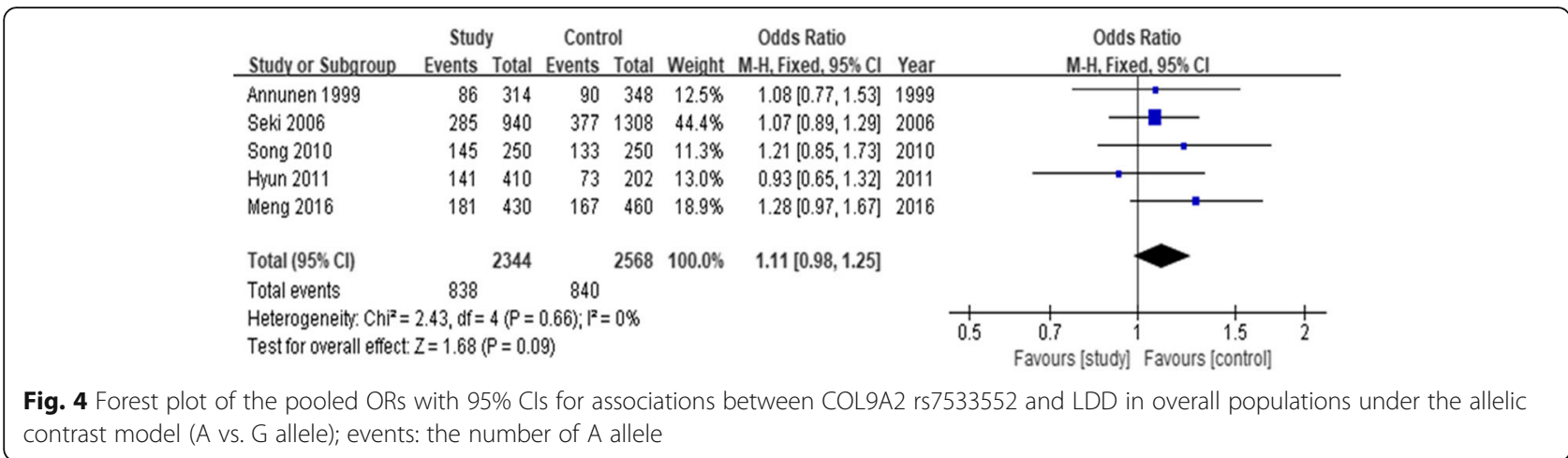

The subgroup analysis of the Asian population was unavailable due to insufficient studies. The forest plot of the allele contrast genetic model indicated the association between rs61734651 polymorphism and LDD predisposition (Fig. 5).

\section{Sensitivity analysis and publication bias}

Sensitivity analysis was performed by excluding one study at a time. For the four SNPs, the results did not alter under all genetic models after sensitivity analysis (Table 4). For rs12077871, when we omitted the study reported by Rathod et al. [16], the heterogeneity was obviously reduced under allele contrast genetic models. For rs61734651, when we excluded the study reported by Paassilta et al. [12], the heterogeneity was significantly reduced under the allele contrast genetic model (Table 5). Sensitivity analysis indicated that our results were robust and consistent.

Publication bias was appraised by applying Begg's funnel plots and Egger's regression test (Fig. 6). The result indicated no significant publication bias under all genetic models (all $P>0.05$ for all models tested).

\section{Discussion}

Various risk factors were widely considered to be related to symptomatic LDD, including environmental, ergonomic, and biometric factors. Nowadays, increasing evidence indicates that genetic factors play critical roles in
LDD [22]. Plenty of recent studies show associations of COL9A2 gene (rs12077871, rs12722877, rs7533552) and COL9A3 gene (rs61734651) polymorphisms with the incidence of LDD. The study reported by Annunen et al. initially suggested that COL9A2 gene polymorphism was associated with LDD in the Finnish population [4]. Some studies were undertaken to replicate this finding $[9,14$, 16]. However, the other studies did not come to the same conclusion [23]. Under the circumstances, a metaanalysis conducted by Zhang et al. investigated the association between COL9A2 gene polymorphism and LDD risk in 2014 [24]. The results indicated no significant association between COL9A2 gene polymorphisms and LDD predisposition. A number of studies have also examined the association between COL9A2 gene polymorphism and LDD in recent years $[19,20]$. However, the previous meta-analysis [24] did not include data from the recent studies, which may lead to inaccuracy in the conclusion. The Cochrane Back Review Group has advocated that a comprehensive meta-analysis needs to be updated with data from the latest studies to be timely [25]. Furthermore, COL9A2 and COL9A3 genes respectively encode $\alpha 2$ and $\alpha 3$ chains of collagen IX, indicating a close relationship between COL9A2 and COL9A3. Several studies have reported that COL9A3 gene polymorphism was associated with susceptibility to LDD [10, 26-28]. However, these published studies have yielded contradictory results rather than conclusive evidence

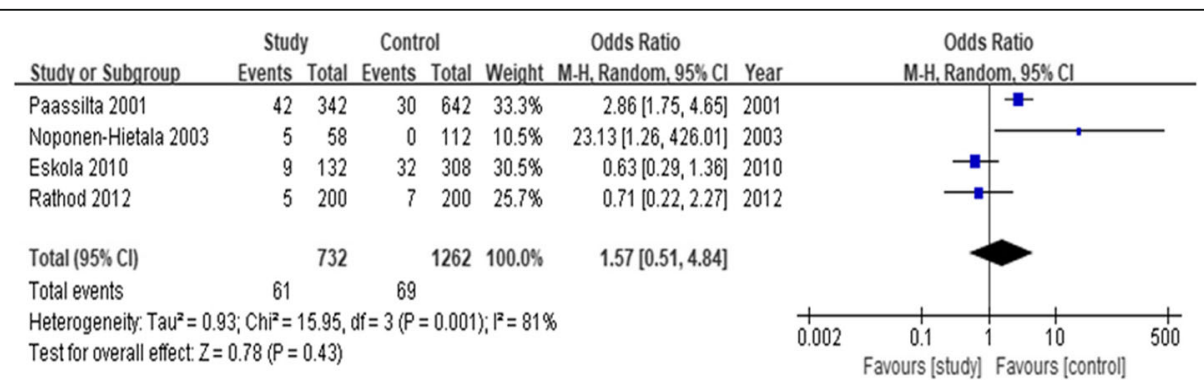

Fig. 5 Forest plot of the pooled ORs with 95\% Cls for associations between COL9A3 rs61734651 and LDD in overall populations under the allelic contrast model ( $T$ vs. C allele); events: the number of C allele 
Table 4 Heterogeneity analysis and Egger regression analysis of COL9A2 and COL9A3 gene polymorphisms (rs12077871, rs12727871, rs7533553, and rs61734657)

\begin{tabular}{|c|c|c|c|c|c|c|c|}
\hline \multirow[t]{2}{*}{ SNP } & \multirow{2}{*}{$\begin{array}{l}\text { Analysis } \\
\text { model }\end{array}$} & \multicolumn{3}{|c|}{ Heterogeneity analysis } & \multicolumn{3}{|c|}{ Egger regression analysis } \\
\hline & & $x^{2}$ & $P$ & $P(\%)$ & $t$ & $95 \% \mathrm{Cl}$ & $P$ \\
\hline rs12077871 & Random & 39.88 & $<0.0001$ & 87.50 & -1.33 & {$[-7.57,2.68]$} & 0.26 \\
\hline rs12722877 & Fixed & 5.73 & 0.125 & 47.70 & -2.78 & {$[-7.51,1.61]$} & 0.11 \\
\hline rs7533552 & Fixed & 1.15 & 0.776 & 0.00 & 0.06 & {$[-5.26,5.41]$} & 0.96 \\
\hline rs61734651 & Random & 15.12 & 0.002 & 81.00 & 0.1 & {$[-12.0,12.6]$} & 0.93 \\
\hline
\end{tabular}

$[15,17,23]$. Thus, we performed a meta-analysis on the associations between COL9A2 and COL9A3 gene polymorphisms and LDD susceptibility. To the best of our knowledge, the current study is the largest sample size of meta-analysis to investigate the association between COL9A2 and COL9A3 gene polymorphisms and LDD predisposition.

Several authors reported that collagen IX provided optimal stability to the lumbar disc cross-linked with collagen II [27] and indicated that collagen IX is crucial for the functional lifespan of intervertebral discs [29]. A role for collagen IX in disc degeneration is supported by human and animal studies [2, 12]. Furthermore, the COL9A2 and COL9A3 genes are highly expressed in intervertebral discs and encode the $\alpha 2$ and $\alpha 3$ chains of type IX collagen, which suggests that they are critical for intervertebral disc metabolism [30]. Mutations of COL9A2 and COL9A3 genes could interfere with the bond between collagen IX and collagen II, leading to decreased stability of the lumbar disc [31]. Thus, it remains plausible that COL9A2 and COL9A3 may be involved in the etiology of LDD through the intervertebral disc metabolism. COL9A2 and COL9A3 gene polymorphisms are supposed to have an impact on gene regulation. However, the precise role of these SNPs is still unknown. Functional analysis of the COL9A2 and

Table 5 The result of sensitivity analysis with each study omitted for rs12077871 in COL9A2 and rs61734651 in COL9A3

\begin{tabular}{llll}
\hline Study omitted & OR & $95 \%$ Cl & $P$ \\
\hline rs12077871 C/T & & & \\
Annunen et al. [4] & 0.61 & {$[0.29,1.30]$} & 0.2 \\
Noponen-Hietala et al. [15] & 0.57 & {$[0.26,1.24]$} & 0.15 \\
Seki et al. [17] & 0.41 & {$[0.15,1.14]$} & 0.09 \\
Song et al. [18] & 0.45 & {$[0.17,1.20]$} & 0.11 \\
Hyun et al. [14] & 0.42 & {$[0.15,1.15]$} & 0.09 \\
Rathod et al. [16] & 1.00 & {$[0.81,1.23]$} & 0.99 \\
rs61734651 C/T & & & \\
Noponen-Hietala et al. [15] & 0.88 & {$[0.30,2.63]$} & 0.002 \\
Paassilta et al. [12] & 0.88 & {$[0.23,3.33]$} & 0.05 \\
Rathod et al. [16] & 0.48 & {$[0.12,1.93]$} & 0.002 \\
$\quad$ Eskola et al. [21] & 0.44 & {$[0.12,1.65]$} & 0.03 \\
\hline OR odds ratio, Cl confidence interval & & &
\end{tabular}

$O R$ odds ratio, $\mathrm{Cl}$ confidence interval
COL9A3 genes might help elucidate the real genetic effect on the etiopathogenesis of LDD.

Our meta-analysis of 10 studies, involving 2102 LDD cases and 2507 controls, found no statistically significant association between COL9A2 gene (rs12077871, rs12722877, rs7533552) and COL9A3 gene (rs61734651) polymorphisms and LDD risk. The previous studies had reported that COL9A2 and COL9A3 gene polymorphisms were related to LDD predisposition in different ethnic population groups. Therefore, we performed a subgroup analysis stratified by ethnicity (Caucasian and Asian). Our results showed rs12722877 was associated with LDD risk in the Asian population under the allele contrast genetic model ( $C$ vs. $G$ ), but not under other genetic models. This finding was in partial accordance with a previous meta-analysis study [23]. We should note that heterogeneity existed in our study in interpreting the results of our meta-analysis. For rs12077871 and rs61734651 polymorphisms, significant heterogeneity was found in all genetic models except the dominant model; for rs12722877 polymorphism, heterogeneity was detected in dominant model models, while for rs7533552 polymorphism, heterogeneity was detected in codominant and recessive models. For rs12077871 polymorphism, the heterogeneity detected in the four genetic models was effectively decreased in sensitivity analysis after excluding the study by Rathod et al. For rs61734651 polymorphism, sensitivity analysis suggested that the study

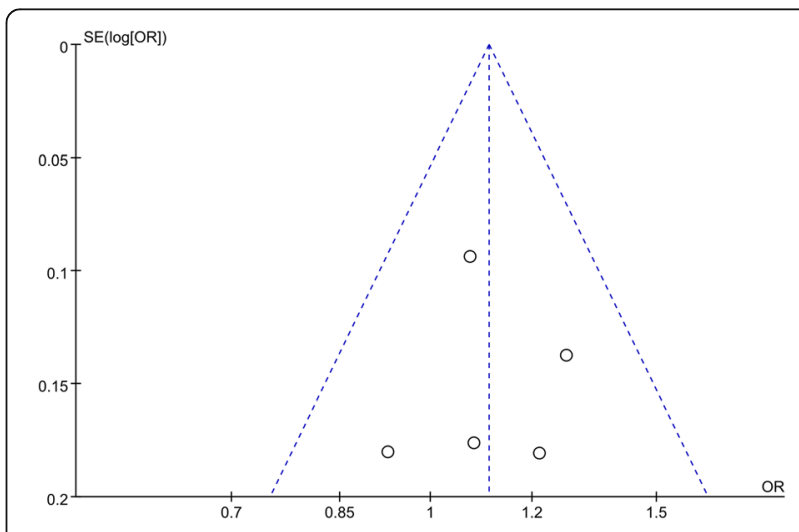

Fig. 6 Funnel plot analysis for publication bias; COL9A2 gene polymorphism (rs7533552) under the allelic contrast model 
of Paassilta et al. was the major source of the heterogeneity. The removal of these datasets did not change the overall results of any genetic models. There are some potential explanations for the presence of heterogeneity, including genetic background, study design, and environment factors. Furthermore, heterogeneity may result from the different phenotype selection and diagnostic criteria of LDD [32]. In view of the heterogeneity, the results of the meta-analysis should be interpreted with caution. A more powerful conclusion needs to be supported by future studies with larger sample sizes.

In our systematic review, increasing the number of studies, which were examined, was possible by extending our search criteria. However, we think that this situation may give rise to further confusion among the results and it may prevent making binding inferences. Several limitations of this study should be acknowledged. First, only English and Chinese documents were searched, while reports in other languages were excluded. This may lead to publication bias. Second, the limited sample size of the pooled studies may exert an influence on their statistical power. Third, we did not perform stratification analysis by age, gender, and environmental factors as a data limitation.

\section{Conclusions}

COL9A2 gene (rs12077871, rs12722877, rs7533552) and COL9A3 gene (rs61734651) polymorphisms were not associated with susceptibility to LDD. The associations of COL9A2 and COL9A3 gene polymorphisms and the risk of LDD could not be fully excluded. Large-scale and well-designed studies are needed to further analyze this field.

\section{Abbreviations \\ COL9A2: Collagen IX alpha 2 chain; COL9A3: Collagen IX alpha 3 chain; LBP: Low back pain; LDD: Lumbar disc degeneration; SNP: Single nucleotide polymorphism}

\section{Acknowledgements}

The authors thank all the participants in this study.

\section{Funding}

This work was supported by the Natural Science Foundation of China (81460353/81560371), Guangxi Natural Science Foundation (2015GXNSFBA139167), and Youth Science Foundation of Guangxi Medical University (GXMUYSF201329).

\section{Availability of data and materials}

Please contact the authors for the data requests.

\section{Authors' contributions}

HJ conceived and designed the study. HW was involved in the data search and selection of data, analyzed the data, and wrote the manuscript. SW was involved in the data search and selection of data and analyzed the data. WC was involved in the data search and analyzed the data. XZ was involved in the data search and selection of data. ZX and QJW analyzed the data and contributed analysis tools. All authors read and approved the final manuscript.

Ethics approval and consent to participate Not applicable.
Consent for publication

Not applicable.

\section{Competing interests}

The authors declare that they have no competing interests.

\section{Publisher's Note}

Springer Nature remains neutral with regard to jurisdictional claims in published maps and institutional affiliations.

\section{Author details}

'Division of Spine Surgery, The First Affiliated Hospital of Guangxi Medical University, No.6 Shuangyong Road, Nanning 530021, China. ${ }^{2}$ Department of Orthopaedic Surgery, The First Affiliated Hospital of Guangxi Medical University, Nanning, China.

Received: 25 November 2017 Accepted: 22 February 2018

Published online: 05 March 2018

\section{References}

1. Shmagel A, Foley R, Ibrahim H. Epidemiology of chronic low back pain in US adults: data from the 2009-2010 National Health and Nutrition Examination Survey. Arthritis Care Res (Hoboken). 2016;68:1688-94.

2. Vassilaki M, Hurwitz EL. Insights in public health: perspectives on pain in the low back and neck: global burden, epidemiology, and management. Hawaii J Med Public Health. 2014:73:122-6.

3. Joud A, Petersson IF, Englund M. Low back pain: epidemiology of consultations. Arthritis Care Res (Hoboken). 2012;64:1084-8.

4. Annunen S, Paassilta P, Lohiniva J, Perala M, Pihlajamaa T, Karppinen J, Tervonen O, Kroger $\mathrm{H}$, Lahde S, Vanharanta $\mathrm{H}$, et al. An allele of COL9A2 associated with intervertebral disc disease. Science. 1999;285:409-12.

5. Kawaguchi $Y$, Kanamori M, Ishihara H, Ohmori K, Matsui H, Kimura T. The association of lumbar disc disease with vitamin-D receptor gene polymorphism. J Bone Joint Surg Am. 2002;84-A:2022-8.

6. Seki S, Kawaguchi Y, Chiba K, Mikami Y, Kizawa H, Oya T, Mio F, Mori M, Miyamoto Y, Masuda I, et al. A functional SNP in CILP, encoding cartilage intermediate layer protein, is associated with susceptibility to lumbar disc disease. Nat Genet. 2005;37:607-12.

7. Jiang H, Qin Z, Zong S, He M, Zhan X, Xiao Z, Wei Q. Vitamin D receptor gene polymorphisms and lumbar disc degeneration: a systematic review and meta-analysis. Eur Spine J. 2017;26:267-77.

8. Rigal J, Leglise A, Barnetche T, Cogniet A, Aunoble S, Le Huec JC. Metaanalysis of the effects of genetic polymorphisms on intervertebral disc degeneration. Eur Spine J. 2017:26:2045-52.

9. Bagheri MH, Honarpisheh AP, Yavarian M, Alavi Z, Siegelman J, Valtchinov VI. MRI phenotyping of COL9A2/Trp2 and COL9A3/Trp3 alleles in lumbar disc disease: a case-control study in south-western Iranian population reveals a significant Trp3-disease association in males. Spine (Phila Pa 1976). 2016;41:1661-7.

10. Toktas ZO, Eksi MS, Yilmaz B, Demir MK, Ozgen S, Kilic T, Konya D. Association of collagen I, IX and vitamin D receptor gene polymorphisms with radiological severity of intervertebral disc degeneration in Southern European ancestor. Eur Spine J. 2015;24:2432-41.

11. Pihlajamaa T, Vuoristo MM, Annunen S, Perala M, Prockop DJ, Ala-Kokko L. Human COL9A1 and COL9A2 genes. Two genes of 90 and $15 \mathrm{~kb}$ code for similar polypeptides of the same collagen molecule. Matrix Biol. 1998;17: 237-41.

12. Paassilta P, Lohiniva J, Goring HH, Perala M, Raina SS, Karppinen J, Hakala M, Palm T, Kroger H, Kaitila I, et al. Identification of a novel common genetic risk factor for lumbar disk disease. JAMA. 2001;285:1843-9.

13. National CASP Collaboration for Qualitative Methodologies: 10 questions to help you make sense of qualitative research. Milton Keynes: Milton Keynes Primary Care Trust; 2006 [https://hhs.hud.ac.uk/lqsu/Useful/critap/ Qualitative\%20Research\%20Checklist/CASP-Qualitative-Research-Checklist-31. 05.13.pdf]. Accessed 15 Jan 2018.

14. Hyun SJ, Park BG, Rhim SC, Bae CW, Lee JK, Roh SW, Jeon SR. A haplotype at the COL9A2 gene locus contributes to the genetic risk for lumbar spinal stenosis in the Korean population. Spine (Phila Pa 1976). 2011:36:1273-8.

15. Noponen-Hietala N, Kyllonen E, Mannikko M, Ilkko E, Karppinen J, Ott J, AlaKokko L. Sequence variations in the collagen IX and XI genes are associated with degenerative lumbar spinal stenosis. Ann Rheum Dis. 2003;62:1208-14. 
16. Rathod TN, Chandanwale AS, Gujrathi S, Patil V, Chavan SA, Shah MN. Association between single nucleotide polymorphism in collagen IX and intervertebral disc disease in the Indian population. Indian J Orthop. 2012; 46:420-6.

17. Seki S, Kawaguchi Y, Mori M, Mio F, Chiba K, Mikami Y, Tsunoda T, Kubo T, Toyama Y, Kimura T, Ikegawa S. Association study of COL9A2 with lumbar disc disease in the Japanese population. J Hum Genet. 2006;51:1063-7.

18. Song HF, Wu ZH, Fei Q, Yan JZ, Liu Z, Zhang JG, Li SG, Qiu GX. Association study of Trp2 allele polymorphism with degenerative disc disease in a Chinese Han nationality. Zhonghua Yi Xue Za Zhi. 2010;90:148-52.

19. Chen T, Li G, Liang K, Jia S. Correlation between lumbar disc degeneration and COL9A2 gene single nucleotide polymorphisms. Chinese J Tissue Eng Res. 2013;17:1695-702.

20. Meng T, Ren Q, Wang JM, Shi H, Zhang ST, Liu MT. Association between COL9A2 Gln326Arg mutations and the development of intervertebral disc disease in a Chinese population. Genet Mol Res. 2016;15(4) https://doi.org/ 10.4238/gmr15048958.

21. Eskola PJ, Kjaer P, Daavittila IM, Solovieva S, Okuloff A, Sorensen JS, Wedderkopp N, Ala-Kokko L, Mannikko M, Karppinen Jl. Genetic risk factors of disc degeneration among 12-14-year-old Danish children: a population study. Int J Mol Epidemiol Genet. 2010;1:158-65.

22. Hemanta D, Jiang XX, Feng ZZ, Chen ZX, Cao YW. Etiology for degenerative disc disease. Chin Med Sci J. 2016;31:185-91.

23. Feng $Y$, Egan B, Wang J. Genetic factors in intervertebral disc degeneration. Genes Dis. 2016;3:178-85.

24. Zhang Z, Zhang J, Ding L, Teng X. Meta-analysis of the association between COL9A2 genetic polymorphisms and lumbar disc disease susceptibility. Spine (Phila Pa 1976). 2014;39:1699-706.

25. Furlan AD, Pennick V, Bombardier C, van Tulder M, Editorial Board CBRG 2009 updated method guidelines for systematic reviews in the Cochrane Back Review Group. Spine (Phila Pa 1976). 2009;34:1929-41.

26. Solovieva S, Lohiniva J, Leino-Arjas P, Raininko R, Luoma K, Ala-Kokko L, Riihimaki H. COL9A3 gene polymorphism and obesity in intervertebral disc degeneration of the lumbar spine: evidence of gene-environment interaction. Spine (Phila Pa 1976). 2002;27:2691-6.

27. Karppinen J, Paakko E, Paassilta P, Lohiniva J, Kurunlahti M, Tervonen O, Nieminen P, Goring HH, Malmivaara A, Vanharanta H, Ala-Kokko L. Radiologic phenotypes in lumbar MR imaging for a gene defect in the COL9A3 gene of type IX collagen. Radiology. 2003;227:143-8.

28. Kalb S, Martirosyan NL, Kalani MY, Broc GG, Theodore N. Genetics of the degenerated intervertebral disc. World Neurosurg. 2012;77:491-501.

29. Kamper M, Hamann N, Prein C, Clausen-Schaumann H, Farkas Z, Aszodi A, Niehoff A, Paulsson M, Zaucke F. Early changes in morphology, bone mineral density and matrix composition of vertebrae lead to disc degeneration in aged collagen IX -/- mice. Matrix Biol. 2016;49:132-43.

30. Seki S, Tsumaki N, Motomura H, Nogami M, Kawaguchi Y, Hori T, Suzuki K, Yahara Y, Higashimoto M, Oya T, et al. Cartilage intermediate layer protein promotes lumbar disc degeneration. Biochem Biophys Res Commun. 2014; 446:876-81.

31. Janeczko L, Janeczko M, Chrzanowski R, Zielinski G. The role of polymorphisms of genes encoding collagen IX and XI in lumbar disc disease. Neurol Neurochir Pol. 2014;48:60-2.

32. Vergroesen PP, Kingma I, Emanuel KS, Hoogendoorn RJ, Welting TJ, van Royen BJ, van Dieen JH, Smit TH. Mechanics and biology in intervertebral disc degeneration: a vicious circle. Osteoarthr Cartil. 2015;23:1057-70.

\section{Submit your next manuscript to BioMed Central and we will help you at every step:}

- We accept pre-submission inquiries

- Our selector tool helps you to find the most relevant journal

- We provide round the clock customer support

- Convenient online submission

- Thorough peer review

- Inclusion in PubMed and all major indexing services

- Maximum visibility for your research

Submit your manuscript at www.biomedcentral.com/submit

) Biomed Central 